\section{Lung abscess: a neglected cause of life threatening haemoptysis} N J Philpott, M A Woodhead, A G Wilson,
F J C Millard

\begin{abstract}
Three cases who presented with life threatening haemoptysis are reported, all of whom required surgery to control the bleeding. In all three patients chronic lung abscess was responsible for the haemoptysis. Even in the absence of typical clinical or radiographic features of an abscess this diagnosis should be considered in any patient presenting with life threatening haemoptysis.
\end{abstract}

(Thorax 1993;48:674-675)

Lung abscess is now an uncommon condition in industralised countries with only eight cases per year identified in one centre in the USA $^{1}$ and only six per year at a British centre. ${ }^{2}$ The typical presentation is either as an acute illness with cough, sputum and chest pain, or more insidiously with weight loss and general malaise. ${ }^{3-5}$ The diagnosis should be considered in the presence of such symptoms associated with chest radiographic shadowing when a predisposing cause is identified such as a period of unconsciousness during which aspiration of oropharyngeal secretions may have occurred. Minor haemoptysis is a common symptom ${ }^{6}$ but it is often forgotten that life threatening haemoptysis can occur. ${ }^{7} \mathrm{We}$ present three previously fit patients who presented with massive haemoptysis resulting from lung abscess.

\section{Case 1}

The Chest Clinic N J Philpott F J C Millard

Department of Diagnostic Radiology A G Wilson

St George's Hospital, London SW17 0QT

Department of Respiratory Medicine, Manchester Royal Infirmary,

Manchester M13 9WL

M A Woodhead

Reprint requests to:

Dr F J C Millard

Received 23 January 1992

Returned to authors

25 March 1992

Revised version received

24 August 1992

Accepted 10 September 1992 two major haemoptyses of at least $500 \mathrm{ml}$ on each occasion which recurred after admission. He gave a history of minor haemoptyses one month before admission; at that time chest radiographic and bronchoscopic examinations were normal. The chest radiograph on admission showed an area of consolidation $2.5 \mathrm{~cm}$ in diameter in the left posterior basal segment. Bronchoscopic findings were normal. A bronchial arteriogram showed abnormal vasculature with a blush appearing in the region of the opacity, but a pulmonary arteriogram was normal with no evidence of pulmonary embolism. Computed tomography showed a $3 \mathrm{~cm}$ well demarcated cavitating mass with patchy consolidation abutting on the pleura in the left lower zone. He was treated by left lower lobectomy. Histological examination showed an abscess cavity, considerable parenchymal scarring, chronic inflammation, and localised bronchiectasis. There was no evidence of malignancy. One year later the patient is well with no recurrence of his haemoptysis.

\section{Case 2}

A 21 year old woman presented with a five day history of haemoptysis and shortness of breath. She had a 10 year history of recurrent minor haemoptyses for which no cause had been found despite extensive investigation. Two years previously she had had an episode of pneumonia. On the day before admission she had further haemoptysis with left basal pleuritic chest pain and breathlessness. She had no fever and no calf pain. A diagnosis of recurrent pulmonary embolism was made and she was given intravenous heparin.

On examination she was breathless at rest (respiratory rate $30 / \mathrm{min}$ ) with a tachycardia. There was no evidence of venous thrombosis of the leg veins. Her haemoglobin level was $13.6 \mathrm{~g} / \mathrm{dl}$. The chest radiograph showed left basal consolidation. Electrocardiography showed a sinus tachycardia but no right heart strain and echocardiographic findings were normal. Arterial blood gas levels on air were: $\mathrm{PaO}_{2} 6 \cdot 1 \mathrm{kPa}, \mathrm{PaCO}_{2} 4 \cdot 6 \mathrm{kPa}, \mathrm{pH} 7 \cdot 37$. There was no evidence of a systemic vasculitis or a mycetoma.

The hypoxia improved with continuous positive airways pressure but she later deteriorated suddenly after a coughing spasm; oxygen saturation fell to $35 \%$ despite inspired oxygen of $100 \%$ and continuous positive airways pressure of $20 \mathrm{~cm} \mathrm{H}_{2} \mathrm{O}$. She was intubated but the left hemithorax failed to expand. Urgent bronchoscopy revealed a clot occluding the left main bronchus which was evacuated and her condition improved. Anticoagulation was reversed. Computed tomography showed a $4 \times 2 \mathrm{~cm}$ irregular mass in the posterior segment of the left lower lobe. Left lower lobectomy was performed two weeks later and an irregular $3 \mathrm{~cm}$ mass was found. Histological examination of the lesion revealed an abscess cavity in communication with the bronchus which was filled with fungal hyphae thought to represent secondary infection of the abscess cavity. She made an uneventful recovery.

\section{Case 3}

A 57 year old previously fit Nigerian man gave an eight day history of haemoptyses associated with right sided pleuritic chest before admission and had received unknown antibiotics there. $\mathrm{He}$ was a non-insulin dependent diabetic and had never smoked. On examination he was pyrexial $\left(39^{\circ} \mathrm{C}\right)$ with a tachycardia. In the chest there was dullness to percussion and reduced air entry at the right lower zone anteriorly and in the axilla. Chest radiography showed consolidation of the middle lobe. The haemoglobin level was pain. He had been in Nigeria until four days 
$11.8 \mathrm{~g} / \mathrm{dl}$ and the white cell count was $12.4 \times$ $10^{9} / 1$. Bronchoscopy showed inflamed bronchial mucosa only. Three weeks later he was well and the radiological changes were improving.

A month later he presented with major haemoptysis associated with the production of foul sputum. The chest radiograph showed persistent consolidation in the middle lobe (fig 1). He had developed clubbing and was febrile at night. His haemoglobin level was $7.8 \mathrm{~g} / \mathrm{dl}$ and erythrocyte sedimentation rate was $80 \mathrm{~mm}$ in the first hour. Sputum culture (including anaerobic culture) and cytological examination gave negative results.

Computed tomography confirmed segmental middle lobe consolidation with an air bronchogram and cavitation (fig 2). He was treated with intravenous ampicillin and erythromycin, and a blood transfusion, and his symptoms improved. However the chest radiograph remained unchanged and, in spite of the radiological appearances which suggested cavitating consolidation, the changes were presumed to be caused by a squamous carcinoma. While awaiting surgery he had a major haemoptysis of about one litre of blood. He had two further large haemoptyses requiring six units of blood to resuscitate him before emergency thoracotomy and middle lobectomy. Histological examination showed a $2 \mathrm{~cm}$ cavity within the lung parenchyma and a few dilated bronchi. The abscess cavity was lined with granulation tissue with signs of old and recent haemorrhage and evidence of acute and chronic inflammation but no vasculitis, granuloma, or malignant cells. He made a good recovery and has had no further haemoptysis.

\section{Discussion}

All three patients presented with severe haemoptysis. The first had a history of cough and recurrent small haemoptyses but his

Figure 1 Chest radiograph of case 3 two months after presentation showing middle lobe consolidation.

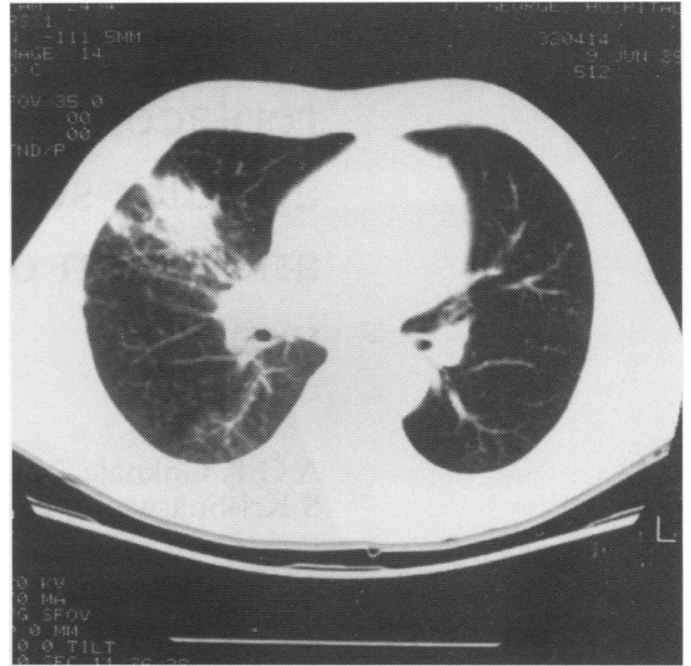

Figure 2 Computed tomogram of case 3.

chest radiograph during this period was normal. The second had a long history of recurrent small haemoptyses and when she presented was thought to be suffering from pulmonary embolism. She was anticoagulated which almost certainly made her condition worse. The third had a history of unresolved pneumonia, thought to be due to an underlying carcinoma in spite of the fact that he was a non-smoker. None of the patients had radiographic changes typical of lung abscess (thick walled cavity with air fluid level). ${ }^{6}$ Computed tomography showed cavitating infective consolidation in the first and third patient but did not exclude a carcinoma. In all these cases the diagnosis was not made until thoracotomy and examination of the surgical specimen.

It is difficult to estimate the number of cases of lung abscesses which present with haemoptysis. These three patients presented to a single cardiothoracic unit over a period of one year and suggest that lung abscess is probably a neglected cause of massive haemoptysis. ${ }^{7}$ The diagnosis of lung abscess should be considered in any patient with massive haemoptysis, particularly if there is a past history of recurrent "sentinel" haemoptysis or pneumonia and undiagnosed lung shadowing. If the haemoptysis becomes life threatening early surgical intervention is indicated.

We are grateful to Drs D Ward and G Griffin for permission to report cases 2 and 3 respectively, and to $M r N$ Wright for his helpful comments.

1 Hagan JL, Hardy JD. Lung abscess revisited; a survey of 184 cases. Ann Surg 1982;197:755-61.

2 Neild JE, Ekyn SJ, Phillips I. Lung abscess and empyema. Qf Med 1985;57:875-22.

3 Chidi CC, Mendelsohn HJ. Lung abscess. F Thorac Cardiovasc Surg 1973;68:168-72.

4 Schweppe HI, Knowles JH, Kane L. Lung abscess; an analysis of the Massachusetts General Hospital cases 1943-1956. N Engl f Med 1961;265:1039-43.

5 Estera AS, Platt MR, Mills LJ, Shaw RR. Primary lung abscess. F Thorac Cardiovasc Surg 1980;79:275-82.

6 Thomas NW, Wilson RF, Puro HE, Arbulu A. Lifethreatening haemoptysis in primary lung abscess. Ann Thorac Surg 1972;14:347-58.

7 Jones DK, Davies RJ. Massive haemoptysis. BMF 1990; 300:889-90. 